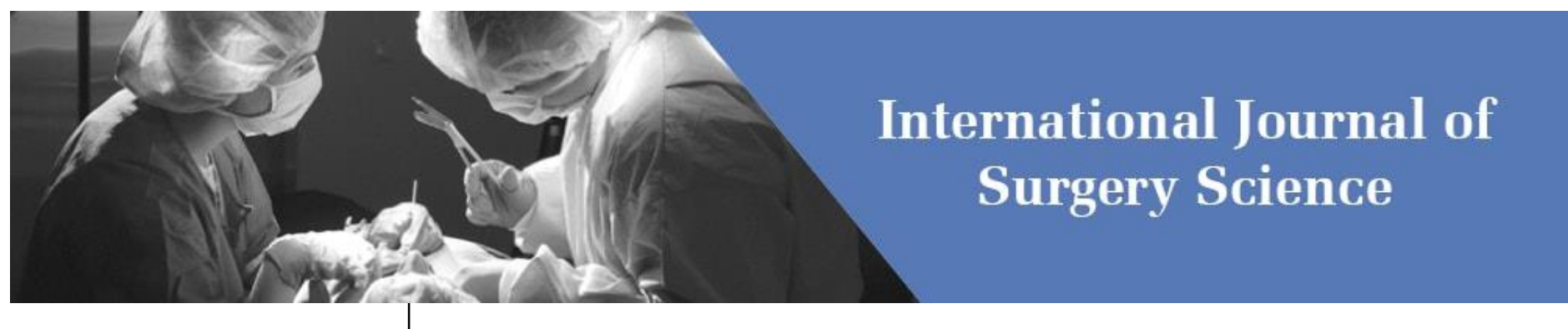

E-ISSN: 2616-3470

P-ISSN: 2616-3462

(C) Surgery Science

www.surgeryscience.com

2020; 4(1): 261-267

Received: 05-11-2019

Accepted: 09-12-2019

\section{Dr. DebanandaTudu}

Associate Professor, Department of General and Laparoscopic Surgery,

VIMSAR, Burla, Odisha, India

Dr. Amaresh Jagadev

Junior Resident, Department of

General and Laparoscopic Surgery,

VIMSAR, Burla, Odisha, India

Corresponding Author:

Dr. Amaresh Jagadev

Junior Resident, Department of

General and Laparoscopic Surgery,

VIMSAR, Burla, Odisha, India

\section{Association of helicobacter pylori infection in carcinoma stomach and peptic ulcer disease: A cross sectional analytical study}

\section{Dr. DebanandaTudu and Dr. Amaresh Jagadev}

DOI: $\underline{\text { https://doi.org/10.33545/surgery.2020.v4.i1e.344 }}$

\section{Abstract}

Background and Aims: The Helicobacter pylori (H. pylori) prevalence in Asian countries is highly variable. We aimed to determine the current $\mathrm{H}$. pylori prevalence, correlate with gastroduodenal diseases and study gastric cancer incidence in western Odisha.

Methods: Out of 3289 patients referred for endoscopy, 2820 eligible patients underwent upper gastrointestinal endoscopy with biopsy and included in the study; $\mathrm{H}$. pylori was considered positive when either of Rapid Urease Test (RUT) or histopathology showed positive result.

Results: The H. pylori prevalence was $29.2 \%$ in overall distribution, $41.1 \%$ in gastritis and or duodenitis, $65.1 \%$ in gastric ulcer, $83.3 \%$ in duodenal ulcer, $19.2 \%$ in gastric polyp and $11.1 \%$ in gastric cancer. The $\mathrm{H}$. pylori in fection was significantly associated with gastritis and or duodenitis $[\mathrm{P}<0.001$; Odds Ratio $(\mathrm{OR})$ 1.53, 95\% Confidence Interval (CI) 1.47-1.59], gastric ulcer ( $\mathrm{P}<0.001$; OR 18.62, 95\% CI 12.40-27.81), duodenal ulcer $(\mathrm{P}<0.001$; OR 48.89, 95\% CI 25.2394.75), gastric polyp $(\mathrm{P}=0.001$; OR $7.66,95 \%$ CI 3.18 18.44) and gastric cancer $(\mathrm{P}=0.005$; OR $3.78,95 \%$ CI 1.82-7.86).

Conclusions: The H. pylori prevalence in Western Odisha was lower than that shown in the previous studies of developing Asian countries, but was significantly high in gastritis and or duodenitis, and peptic ulcers. Similarly, the gastric cancer incidence was also low in Western parts of Odisha and was significantly associated with $\mathrm{H}$. pylori. Further study is needed to establish the association of $\mathrm{H}$. pylori with gastric cancer in Western Odisha.

Keywords: helicobacter pylori, peptic ulcer disease, carcinoma stomach

\section{Introduction}

Gastritis is one of the most common problem in day to day medical practice and incidence of gastric cancer is in an increasing trend. Helicobacter pylori is found in association with $90-95 \%$ of duodenal ulcer and in $60-75 \%$ of patients with gastric ulcer ${ }^{[1]}$.

Though a wide range of etiological factors play a role, the exact cause of peptic ulcer disease is inconclusive. Helicobacter pylori is associated with chronic active gastritis in virtually $100 \%$ of patients ${ }^{[2]}$. It is also associated with $88 \%$ of intestinal type and $55 \%$ of gastric type of gastric cancer. Recently, warren and Marshall received Nobel prize for their outstanding work on Helicobacter pylori in the year 2005.

Recent works like eradication of Helicobacter pylori leading to healing of peptic ulcer diseases and reduction of ulcer recurrence rate have given encouraging results and proved beyond doubt an association between Helicobacter pylori infection and acid peptic diseases ${ }^{[3]}$. H. pylori infection also has been associated with the development of gastric non-Hodgkin's lymphoma and with another lymphoproliferative disorder, gastric mucosa associated lymphoid tissue (MALT) lymphoma (MALToma) ${ }^{[4,5,6]}$. Importantly, gastric MALToma patients with antibiotics that eradicate $H$. pylori often leads to regression of the tumor ${ }^{[7,12]}$.

The prevalence of association of $\mathrm{H}$. pylori is more in low socioeconomic status group than middle and high socioeconomic status group. Also the association of $\mathrm{H}$. pylori is high in smokers and NSAIDS users but in alcoholics the association of $\mathrm{H}$. pylori varies in different studies.

Though many bacterial organisms were indeed found earlier in gastric mucosa associated with gastroduodenal diseases, it was Warren and Marshall (1984) who isolated these Gm-ve organisms from these cases and found a relation to its causation. The role of $\mathrm{H}$. pylori in the 
pathogenesis of acid peptic diseases and carcinoma stomach is unclear. Evidence to support a role of this organism is reviewed here in and includes:

The major structural, functional and pathophysiological changes occurring in the mucosa of infected individuals and higher prevalence of $\mathrm{H}$. pylori in subjects with acid peptic diseases and carcinoma stomach ${ }^{[13,17]}$.

Eradication of the bacteria leading to clinical improvement and corresponding mucosal restoration in subjects ${ }^{[18]}$.

The new concept of infective role of Helicobacter pylori for gastritis and carcinoma stomach has got the respectable attention by over-whelming reports from Marshall (2005) and the ongoing research in this field generated our interest in carrying out the project on "Association of Helicobacter pylori infection in carcinoma stomach and peptic ulcer disease" to prove that $\mathrm{H}$. pylori, despite its normally innocent habitat can be alarmingly dangerous as either the primary agent or agent which is responsible for recurrence and recrudescence.

The present study was under taken to evaluate the role of $\mathrm{H}$. pylori in carcinoma stomach and peptic ulcer disease.

\section{Background and aim of the study}

Asian countries shows is highly variable $\mathrm{H}$. pylori prevalence. We aimed to determine the current $H$. pylori epidemiology, correlate with gastroduodenal diseases and study of gastric cancer in patients coming to V.S.S. Institute of medical science and research, Burla, Sambalpur.

\section{Rational of the study}

Epidemiological studies point to a role for H. pylori, although its importance is disputed.

This study will helpful in finding out the prevalence and distribution of $\mathrm{H}$. pylori in carcinoma stomach and peptic ulcer diseases and gastritis which will make a humble addition to the past works.

\section{Objective}

Primary Objective: To find out the prevalence of $\mathrm{H}$. pylori infection in carcinoma stomach and peptic ulcer disease.

Secondary Objective: To compare the association of H. pylori with carcinoma stomach and peptic ulcer disease.

\section{Materials and Methods}

The present study titled "Association of Helicobacter pylori infection in carcinoma stomach and peptic ulcer disease: A cross sectional analytical study" was conducted in the Department of General surgery of V.S.S. Institute Medical Science and Research, Burla during the period of 2017 to 2019.

A total of 2820 patients were eligible for study out of 3289 patients undergone upper gastrointestinal (GI) endoscopy. The exclusion criteria for the study were: 1) patients who had received proton pump inhibitors or histamine 2-receptor antagonists for a minimum of 2 weeks and antibiotics for 4 weeks prior to the study; patients who had Antacid, Bismuth, Non-steroidal anti-inflammatory drugs or had $H$. pylori eradication therapy in the past, 2) patients with a diagnosis of portal hypertensive gastropathy and esophageal varices 3) patients with an abnormal coagulation profile, 4) patients with severe medical co-morbidities like COPD, heart failure, kidney failure, etc. and 5) patients not giving an informed consent for the study.
Detail history, physical examination and relevant investigations were done as per the proforma.

All eligible 2820 subjects underwent upper GI endoscopy at V.S.S. Institute of medical science and research, Burla, Sambalpur district of Odisha during the period of November2017 to October 2018.

The informed consent was taken from all study subjects and the study protocol was approved by the ethics committees of VIREC.

Upper GI endoscopy was performed in each patient and Two gastric antral biopsy specimens were taken. One specimen from each patient was subjected to Rapid Urease Test (H-P test Commercial Kit) and the other one was $10 \%$ formalin fixed for histopathological examination. Hematoxylin and Eosin stain was used for histopathological examination and $\mathrm{H}$. pylori was studied using Warthin Starry stain.

\section{Details of Endoscopy and Procedure}

Patient was kept nil per oral the night before. The details of endoscopic procedure and its risks were explained to the patients in their own language and a written consent was obtained from the patients Lignocaine $2 \%$ spray was used as local anesthesia for anaesthetizing pharynx.

The endoscopic findings were recorded and with biopsy forceps; two pieces of antral tissues taken. Rapid urease test is performed in one chunk of tissue and other bit of tissue was preserved in $10 \%$ formalin for histological examination

\section{Details of Rapid Urease Test (RUT):}

It is done with H-P test kit, a commercially available kit, product of Lenus Medicare \& Research (OPC) Private Limited, Kolkata, India.

\section{Principle}

High concentration of urea is present in gastric mucosa. Urease produced by $\mathrm{H}$. pylori reacts with urea in the presence of water molecules and $\mathrm{H}^{+}$ions producing ammonia and bicarbonate. Ammonia in turn raises the $\mathrm{pH}$ of the medium immediately. This change of $\mathrm{pH}$ can be readily detected by $\mathrm{pH}$ indicator e.g. phenol red.

\section{Composition}

H-P test kit contains (1) urea, (2) pH indicator, (3) Stabilizing agent, (4) Bacteriostatic agent (does not react on H. pylori)

\section{Procedure of Test}

It was done with H-P test rapid urease test kit.

After taking out of the fridge, H-P test kit, having yellow color was checked and allowed to attain room temperature in order to enhance chemical reaction.

Biopsy was taken from pyloric antrum adjacent to the opening avoiding the areas of erosion and ulceration.

Urease enzyme of $\mathrm{H}$. pylori reacts with urea of gel media changes the color from yellow to red or pink elevating $\mathrm{pH}$.

\section{Interpretation}

Examination of the color change from yellow to red or pink at 30-minute intervals for 4 hours was observed. Most of the positive cases showed the result within 4 hours. The observation was continued up to 24 hours.

If the color changed from yellow to red or pink, the result was positive i.e. presence of $\mathrm{H}$. pylori is confirmed in the biopsy. If the color did not change, the result was negative. 


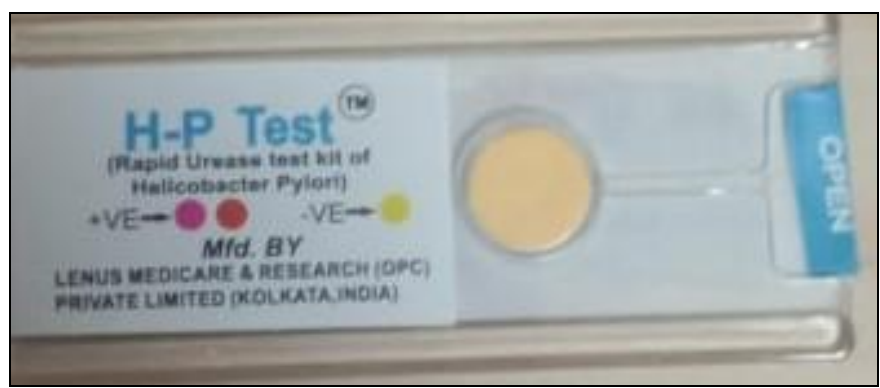

Fig 1: Freshly opened Rapid Urease Test Kit.

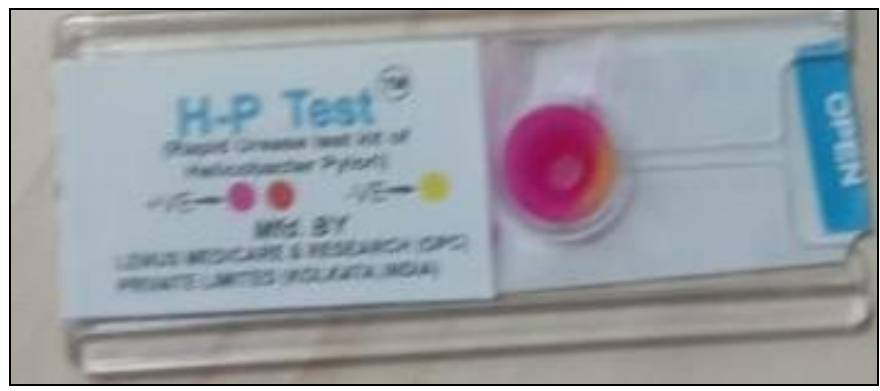

Fig 2: H. pylori positive in Gastric biopsy specimen.

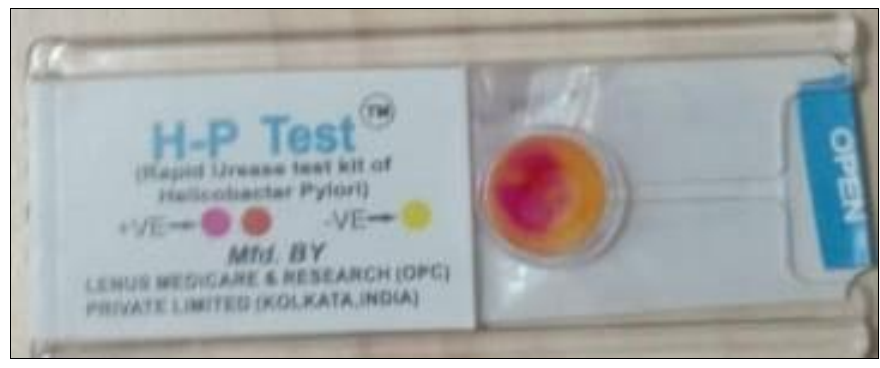

Fig 3: H. pylori positive in Antral biopsy specimen.

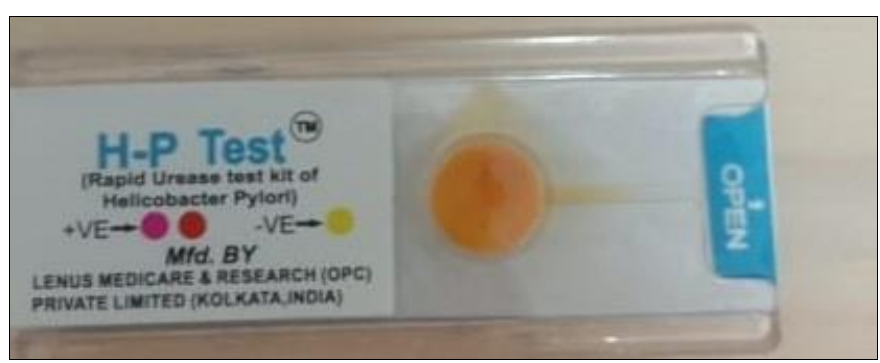

Fig 4: H. pylori negative in Gastric biopsy specimen.

\section{Histopathology \& Tissue Processing}

In each patient, two endoscopic biopsies taken from the stomach were sent in $10 \%$ formalin for histopathology. The tissue biopsies were routinely processed. All the tissue had been studied with Hematoxylin-eosin and Giemsa for histopathological examination and warthin Starry stain for $\mathrm{H}$. pylori study.

\section{Methods of Staining}

Haematoxylin and Eosin (Alan Stevens And Bancroft, 1982)

- Nuclei - Blue black

- Cytoplasm - Pink

- H. pylori - Pink rods

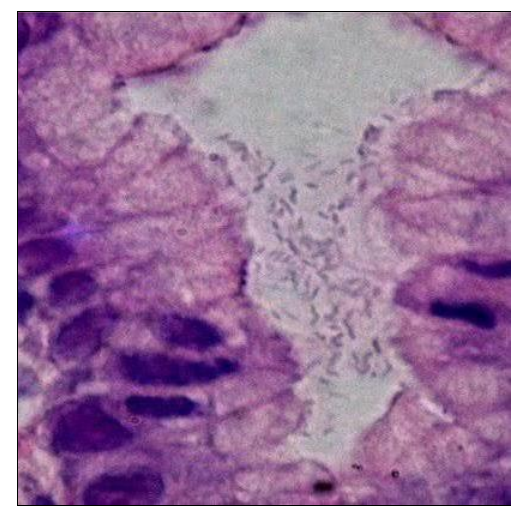

Fig 5: Demonstration of H. pylori by H\&E stain (High power view)

\section{Giemsa Stain (Alan Stevens and Bancroft, 1982)}

- Nuclei-Blue

- Cytoplasm - Pale blue

- H. pylori - Dark blue rods

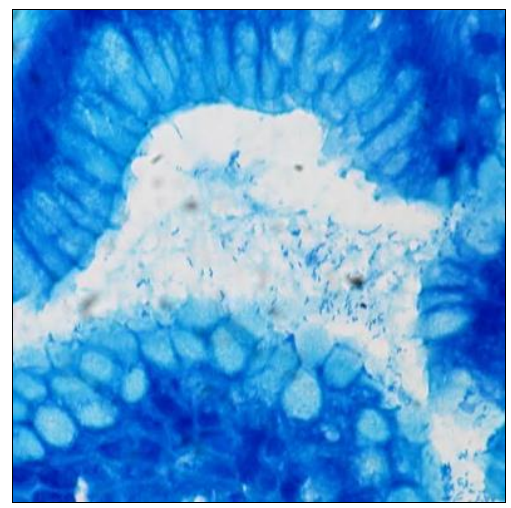

Fig 6: Demonstration of H. pylori in Gastric biopsy specimen by Giemsa staining

3. Warthin-Starry Stain (Manual of histologic \& special staining techniques AFIP, $2^{\text {nd }}$ Edn. 1960)

- Bacteria - Black

- Background - Pale yellow to light brown.

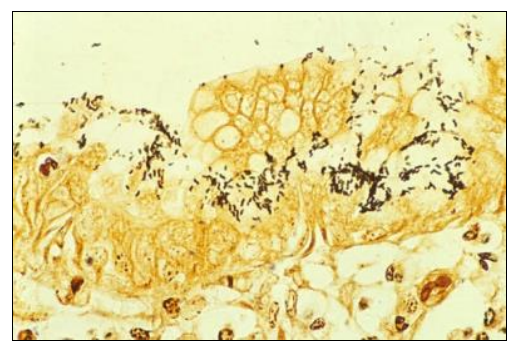

Fig 7: Demonstration of H. pylori by Warthin-Starry stain. (High power view)

Prospectively all data of endoscopy and the H. pylori reports were recorded in a personal computer and the results of $\mathrm{H}$. pylori were categorized according to the age group, gender and different diagnosis. All the data were analysed using SPSS 16.0 software. All data were analyzed statistically by using Chisquare test or Fisher exact test, Odds Ratio (OR) and 95\% Confidence Interval (CI), as appropriate. The patients with normal endoscopic findings were taken as the control group. The $\mathrm{P}$ value less than 0.05 was considered to be statistically significant.

Out of 2820 eligible patients, males were $54 \%$ and females were $46 \%$ with the mean age of 44.6 years \pm 17.6 ranging from 13 to 
88 years. The distribution of the endoscopic findings were as follows: normal $20.6 \%$, esophagitis $10.1 \%$, gastritis and or duodenitis $59.5 \%$, peptic ulcer $5.10 \%$ (gastric ulcer $3 \%$, duodenal ulcer $2.1 \%$ ), gastric polyp $0.9 \%$, duodenal polyp $0.2 \%$, esophageal cancer $1 \%$, gastric cancer $1.9 \%$, duodenal cancer $0.1 \%$, achalasia cardia $0.1 \%$, hiatus hernia $0.2 \%$, duodenal diverticulum $0.1 \%$ and esophageal stricture $0.1 \%$. Table 1 shows distribution of different diagnosis according to the gender and mean age. The distribution of different diagnosis according to age group is shown in table 2 .

The overall prevalence of $\mathrm{H}$. pylori infection was $29.2 \%$; the males had $29.1 \%$ and females had $29.3 \%$ of $\mathrm{H}$. pylori, showing the similar distribution of $\mathrm{H}$. pylori among the gender (table 3 ).

The prevalence of $H$. pylori in $\geq 20$ years age group (20-29 years)

$24.3 \%$, 30-39 years $24.3 \%$, 40-49 years $32.4 \%$, 50-59 years $34 \%, 60-69$ years $27.2 \%$ and $\geq 70$ years $31 \%$ ) was greater than that in $<20$ years age group $(15.3 \%)$, which was statistically significant $(\mathrm{P}=0.001)$ [table 4].

The H. pylori infection was significantly associated with gastritis and or duodenitis $[P<0.001$; Odds Ratio (OR) 1.53 , 95\% Confidence Interval (CI) 1.47-1.59], gastric ulcer $(\mathrm{P}<0.001$; OR 18.62, 95\% CI 12.40-27.81), duodenal ulcer $(\mathrm{P}<0.001$; OR 48.89, 95\% CI 25.23-94.75), gastric polyp ( $\mathrm{P}=0.001$; OR 7.66, 95\% CI 3.18-18.44) and gastric cancer ( $\mathrm{P}=0.005$; OR 3.78, 95\% CI 1.82-7.86), but there is inverse relationship of $\mathrm{H}$. pylori association with esophagitis $(\mathrm{P}=0.058$; OR 0.35 , 95\% CI 0.09 1.29).

The distribution of $\mathrm{H}$. pylori infection among different diagnosis was as follows: normal $2.4 \%$, esophagitis $0.7 \%$, gastritis and or duodenitis $41.1 \%$, gastric ulcer $65.1 \%$, duodenal ulcer $83.3 \%$, gastric polyp $19.2 \%$, duodenal polyp $0 \%$, esophageal cancer $0 \%$, gastric cancer $11.1 \%$, duodenal cancer $0 \%$, achalasia cardia $0 \%$, hiatus hernia $0 \%$, duodenal diverticulum $0 \%$ and esophageal stricture $0 \%$ as shown in table 5 .

Table 1: Distribution of different diagnosis according to the gender and mean age

\begin{tabular}{|c|c|c|c|c|c|c|}
\hline Total $(\mathbf{N = 2 8 2 0})$ & $\boldsymbol{\%}$ & $\begin{array}{c}\text { Male } \\
(\mathbf{n = 1 5 2 4})\end{array}$ & $\mathbf{\%}$ & $\begin{array}{c}\text { Female } \\
(\mathbf{n = 1 2 9 6})\end{array}$ & $\mathbf{\%}$ & Mean age in years (SD) \\
\hline Normal $(\mathrm{n}=582)$ & 20.6 & 280 & 48.1 & 302 & 51.9 & $38.6(+/-15.8)$ \\
\hline Esophagitis $(\mathrm{n}=285)$ & 10.1 & 205 & 71.9 & 80 & 28.1 & $51.7(+/-16.9)$ \\
\hline Gastritis and or duodenitis $(\mathrm{n}=1677)$ & 59.5 & 861 & 51.3 & 816 & 48.7 & $46.5(+/-17)$ \\
\hline Gastric ulcer $(\mathrm{n}=86)$ & 3 & 50 & 58.1 & 36 & 41.9 & $55.1(+/-17.6)$ \\
\hline Duodenal ulcer $(\mathrm{n}=60)$ & 2.1 & 45 & 75 & 15 & 25 & $46.3(+/-18.7)$ \\
\hline Gastric polyp $(\mathrm{n}=26)$ & 0.9 & 14 & 53.8 & 12 & 46.2 & $49.0(+/-18.0)$ \\
\hline Duodenal polyp $(\mathrm{n}=5)$ & 0.2 & 4 & 80 & 1 & 20 & $55.4(+/-5.3)$ \\
\hline Esophageal cancer $(\mathrm{n}=28)$ & 1 & 16 & 57.1 & 12 & 42.9 & $65.7(+/-9.5)[$ median age:68] \\
\hline Gastric cancer $(\mathrm{n}=54)$ & 1.9 & 40 & 74.1 & 14 & 25.9 & $66.7(+/-12.5)[$ median age:68] \\
\hline Duodenal cancer $(\mathrm{n}=4)$ & 0.1 & 2 & 50 & 2 & 50 & $45.7(+/-23.6)[$ median age:44] \\
\hline Achalasia cardia $(\mathrm{n}=2)$ & 0.1 & 1 & 50 & 1 & 50 & $62.0(+/-10.4)$ \\
\hline Hiatus hernia $(\mathrm{n}=6)$ & 0.2 & 3 & 50 & 3 & 50 & $45.9(+/-19.2)$ \\
\hline Duodenal diverticulum $(\mathrm{n}=3)$ & 0.1 & 2 & 66.7 & 1 & 33.3 & $50.5(+/-19.3)$ \\
\hline Esophageal stricture $(\mathrm{n}=2)$ & 0.1 & 1 & 50 & 1 & 50 & $66.5(+/-7.8)$ \\
\hline
\end{tabular}

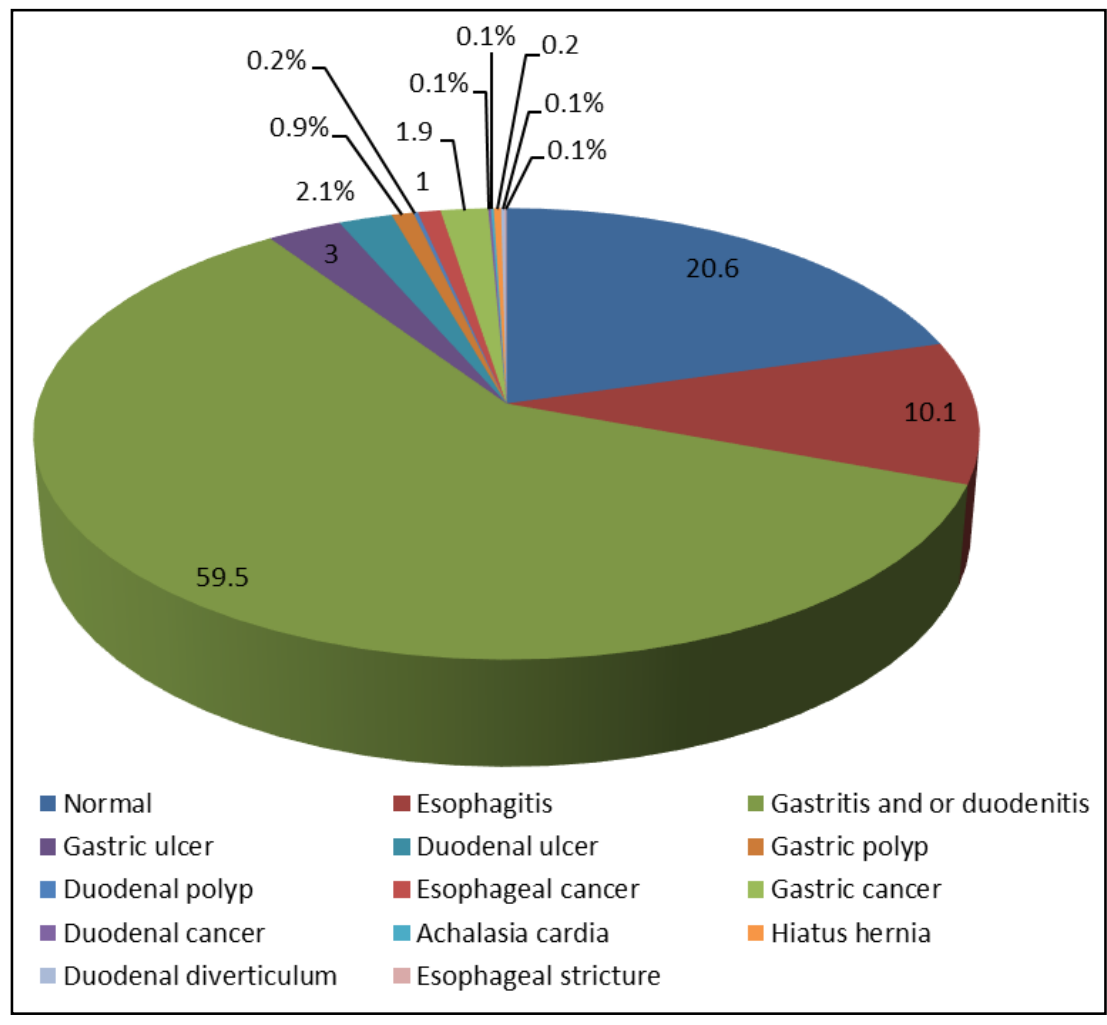

Chart 1: Percentage of different diagnosis 


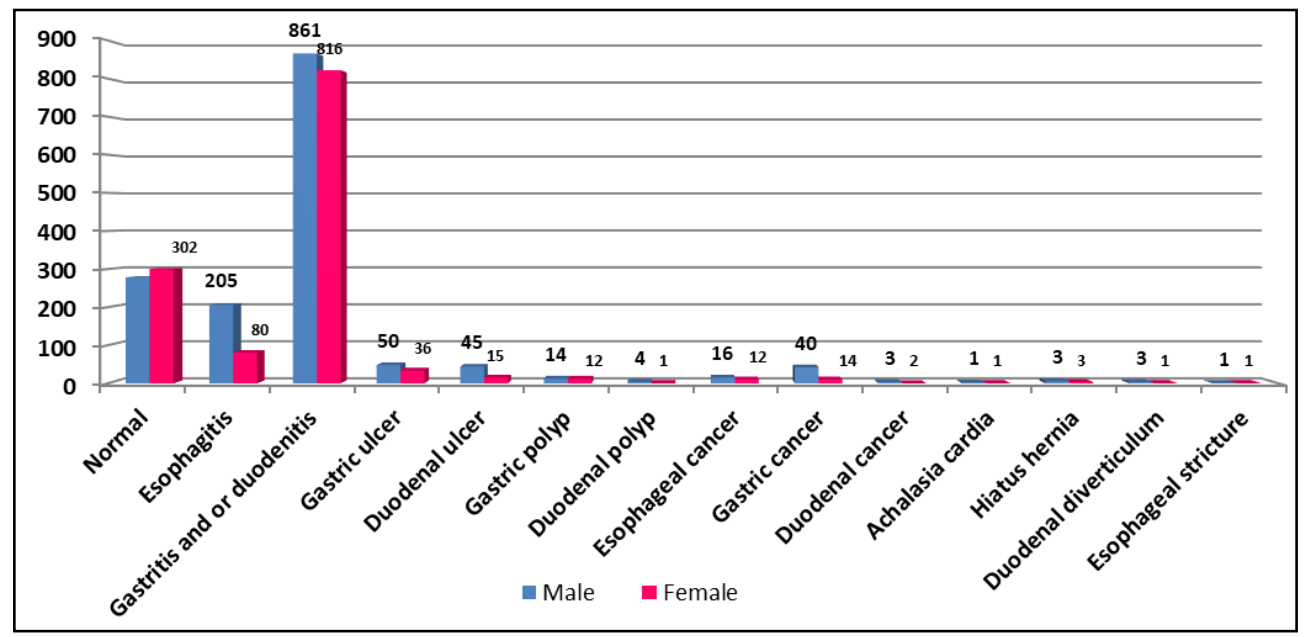

Chart 2: Distribution of different diagnosis according to the gender

Table 2: Distribution of different diagnosis according to age group

\begin{tabular}{|c|c|c|c|c|c|c|c|}
\hline Total $(\mathrm{N}=2820)$ & $<20$ years & 20-29 years & 30-39 years & 40-49 years & 50-59 years & 60-69 years & $\geq 70$ years \\
\hline Normal $(n=582) ;(20.6 \%)$ & $38(38.8 \%)$ & $176(35.6 \%)$ & $120(24.6 \%)$ & $97(18.7 \%)$ & $69(14.7 \%)$ & $54(13.3 \%)$ & $28(8 \%)$ \\
\hline Esophagitis $(\mathrm{n}=285) ;(10.1 \%)$ & $10(10.2 \%)$ & $24(4.8 \%)$ & $24(4.9 \%)$ & $64(12.3 \%)$ & $56(11.9 \%)$ & $66(16.3 \%)$ & $41(11.8 \%)$ \\
\hline Gastritis and/or duodenitis(n=1677); (59.6\%) & $46(46.9 \%)$ & $270(54.6 \%)$ & $320(65.7 \%)$ & $320(61.8 \%)$ & $288(61.2 \%)$ & $225(55.5 \%)$ & $210(60.3 \%)$ \\
\hline Gastric ulcer $(\mathrm{n}=86) ;(3 \%)$ & $1(1 \%)$ & $8(1.6 \%)$ & $7(1.4 \%)$ & $14(2.7 \%)$ & $15(3.2 \%)$ & $25(6.1 \%)$ & $16(4.6 \%)$ \\
\hline Duodenal ulcer $(\mathrm{n}=60) ;(2.1 \%)$ & $1(1 \%)$ & $14(2.8 \%)$ & $7(1.4 \%)$ & $10(1.9 \%)$ & $14(3 \%)$ & $5(1.2 \%)$ & $9(2.6 \%)$ \\
\hline Gastric polyp $(\mathrm{n}=26) ;(0.9 \%)$ & $2(2 \%)$ & $1(0.2 \%)$ & $6(1.2 \%)$ & $2(0.4 \%)$ & $5(1 \%)$ & $6(1.5 \%)$ & $4(1.1 \%)$ \\
\hline Duodenal polyp $(\mathrm{n}=5) ;(0.2 \%)$ & $0(0 \%)$ & $0(0 \%)$ & $0(0 \%)$ & $1(0.2 \%)$ & $2(0.4 \%)$ & $2(0.5 \%)$ & $0(0 \%)$ \\
\hline Esophageal cancer $(\mathrm{n}=28) ;(1 \%)$ & $0(0 \%)$ & $0(0 \%)$ & $0(0 \%)$ & $2(0.4 \%)$ & $4(0.8 \%)$ & $11(2.7 \%)$ & $11(3.1 \%)$ \\
\hline Gastric cancer $(n=54) ;(1.9 \%)$ & $0(0 \%)$ & $0(0 \%)$ & $0(0 \%)$ & $4(0.8 \%)$ & $14(3 \%)$ & $10(2.5 \%)$ & $26(7.5 \%)$ \\
\hline Duodenal cancer $(n=4) ;(0.1 \%)$ & $0(0 \%)$ & $1(0.2 \%)$ & $0(0 \%)$ & $1(0.2 \%)$ & $1(0.2 \%)$ & $0(0 \%)$ & $1(0.3 \%)$ \\
\hline Achalasia cardia $(\mathrm{n}=2) ;(0.1 \%)$ & $0(0 \%)$ & $0(0 \%)$ & $0(0 \%)$ & $0(0 \%)$ & $1(0.2 \%)$ & $1(0.2 \%)$ & $0(0 \%)$ \\
\hline Hiatus hernia $(n=6) ;(0.2 \%)$ & $0(0 \%)$ & $0(0 \%)$ & $2(0.4 \%)$ & $2(0.4 \%)$ & $0(0 \%)$ & $0(0 \%)$ & $2(0.6 \%)$ \\
\hline Duodenal diverticulum $(\mathrm{n}=3) ;(0.1 \%)$ & $0(0 \%)$ & $0(0 \%)$ & $1(0.2 \%)$ & $1(0.2 \%)$ & $1(0.2 \%)$ & $0(0 \%)$ & $0(0 \%)$ \\
\hline Esophageal stricture $(\mathrm{n}=2) ;(0.1 \%)$ & $0(0 \%)$ & $0(0 \%)$ & $0(0 \%)$ & $0(0 \%)$ & $0(0 \%)$ & $1(0.2 \%)$ & $1(0.3 \%)$ \\
\hline
\end{tabular}

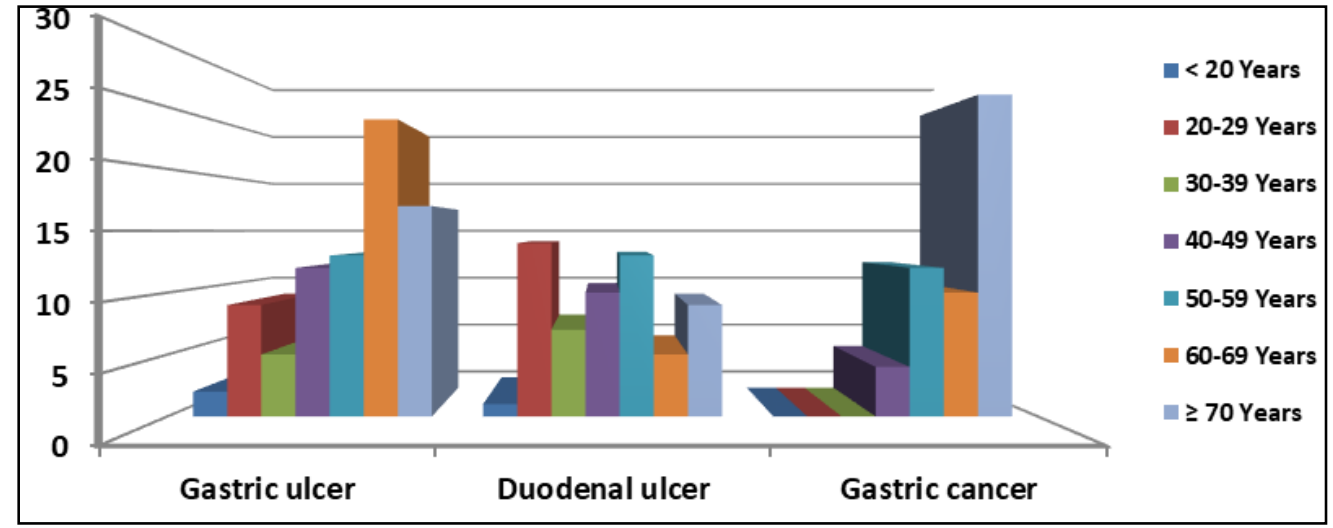

Chart 3: Distribution of carcinoma stomach and peptic ulcer disease in different age group

Table 3: Distribution of H. pylori according to the gender

\begin{tabular}{|c|c|c|c|}
\hline & H. pylori positive & H. pylori negative & P value \\
\cline { 1 - 3 } Male $(\mathrm{n}=1524)$ & $444(29.1 \%)$ & $1080(70.9 \%)$ & \multirow{2}{*}{0.8} \\
\hline Female $(\mathrm{n}=1296)$ & $380(29.3 \%)$ & $916(70.7 \%)$ & \\
\hline
\end{tabular}

Table 4: Distribution of H. pylori according to the age group

\begin{tabular}{|c|c|c|c|c|}
\hline \multirow{8}{*}{$\begin{array}{l}\text { Age Groups } \\
\text { (In Years) }\end{array}$} & Total $(\mathrm{N}=\mathbf{2 8 2 0})$ & H. pylori positive $(\mathrm{n}=824)[29.2 \%]$ & H. pylori negative $(\mathrm{n}=1996)[70.8 \%]$ & \multirow{8}{*}{$\begin{array}{l}\text { P value } \\
-0.001\end{array}$} \\
\hline & $<20(\mathrm{n}=98)$ & $15[15.3 \%]$ & $83[84.7 \%]$ & \\
\hline & $20-29(n=494)$ & $120[24.3 \%]$ & $374[75.7 \%]$ & \\
\hline & $30-39(n=487)$ & $143[24.3 \%]$ & $344[75.7 \%]$ & \\
\hline & $40-49(n=518)$ & $168[32.4 \%]$ & $350[67.6 \%]$ & \\
\hline & $50-59(n=470)$ & $160[34 \%]$ & $310[66 \%]$ & \\
\hline & $60-69(n=405)$ & $110[27.2 \%]$ & $295[72.8 \%]$ & \\
\hline & $\geq 70(\mathrm{n}=348)$ & $108[31 \%]$ & $240[69 \%]$ & \\
\hline
\end{tabular}


Table 5: Distribution of H. pylori according to different diagnosis

\begin{tabular}{|c|c|c|c|c|}
\hline Total $(\mathbf{N}=\mathbf{2 8 2 0})$ & H. pylori positive & H. pylori negative & P value* & Odds ratio (**95\% CI) \\
\hline Normal $(\mathrm{n}=582)$ & $14(2.4 \%)$ & $568(97.6 \%)$ & & \\
\hline Esophagitis $(\mathrm{n}=285)$ & $2(0.7 \%)$ & $283(99.3 \%)$ & 0.058 & $0.35(0.09-1.29)$ \\
\hline Gastritis \&/OR Duodenitis $(\mathrm{n}=1677)$ & $690(41.1 \%)$ & $987(58.9 \%)$ & $<0.001$ & $1.53(1.47-1.59)$ \\
\hline Gastric ulcer $(\mathrm{n}=86)$ & $56(65.1 \%)$ & $30(34.9 \%)$ & $<0.001$ & $18.62(12.40-27.81)$ \\
\hline Duodenal ulcer $(\mathrm{n}=60)$ & $50(83.3 \%)$ & $10(16.7 \%)$ & $<0.001$ & $48.89(25.23-94.75)$ \\
\hline Gastric polyp $(\mathrm{n}=26)$ & $5(19.2 \%)$ & $21(80.8 \%)$ & 0.001 & \\
\hline Duodenal polyp ( $\mathrm{n}=5)$ & $0(0 \%)$ & $5(100 \%)$ & 1.0 & \\
\hline Esophageal cancer $(\mathrm{n}=28)$ & $0(0 \%)$ & $28(100 \%)$ & 1.0 & \\
\hline Gastric cancer( $\mathrm{n}=54)$ & $6(11.1 \%)$ & $48(88.9 \%)$ & 0.005 & $3.78(1.82-7.86)$ \\
\hline Duodenal cancer $(\mathrm{n}=4)$ & $0(0 \%)$ & $4(100 \%)$ & 1.0 & \\
\hline Achalasia cardia $(\mathrm{n}=2)$ & $0(0 \%)$ & $2(100 \%)$ & 1.0 & \\
\hline Hiatus hernia $(\mathrm{n}=6)$ & $0(0 \%)$ & $6(100 \%)$ & 1.0 & \\
\hline Duodenal diverticulum $(\mathrm{n}=3)$ & $0(0 \%)$ & $3(100 \%)$ & 1.0 & \\
\hline Esophageal stricture $(\mathrm{n}=2)$ & $0(0 \%)$ & $2(100 \%)$ & 1.0 & \\
\hline
\end{tabular}

$\$$ Patients with normal endoscopic findings were taken as the control group.

*P value obtained using Chi square test or Fischer exact test as appropriate

** $95 \%$ confidence interval

\section{Discussion}

More than half of patients referred for endoscopy had gastritis and or duodenitis, although one fifth patients had normal findings and one tenth patients had esophagitis; the prevalence of peptic ulcer disease was $5.1 \%$, gastric cancer $1.9 \%$ and esophageal cancer $1 \%$ showing that there is no wide difference of prevalence between peptic ulcer disease and malignancy.

There is higher prevalence of $\mathrm{H}$. pylori in developing countries than the developed countries, which may be due to poor socioeconomic status and hygiene practices.

Our current study demonstrated that $\mathrm{H}$. pylori prevalence of $29.2 \%$. This is in contrary to the age-old data of high prevalence of $\mathrm{H}$. pylori in developing Asian countries. This could be attributed to change in lifestyles, Westernization and rampant use of proton pump inhibitors and antibiotics.

However, our study didn't show any significant difference of $\mathrm{H}$. pylori prevalence among the male and female population under study.

In our study, the age group $<20$ years had lower prevalence (15.3\%) of $\mathrm{H}$. pylori than that of $\geq 20$ years group, which showed the highest prevalence (34\%) being seen in the age group of 5059 years followed by $32.4 \%$ in $40-49$ years group. This difference in $\mathrm{H}$. pylori prevalence among different age group was statistically significant and it shows increasing trend of $\mathrm{H}$. pylori prevalence with aging

Our study showed that there is significant association of $\mathrm{H}$. pylori with Gastric polyp along with gastritis and duodenitis.

Our study showed that prevalence of gastric cancer is $1.9 \%$ and overall H. pylori positivity is $29.2 \%$. The gastric cancer was associated with $\mathrm{H}$. pylori positivity in $11.1 \%$ which was statistically significant when compared to $2.4 \%$ of $\mathrm{H}$. pylori positivity in normal subjects taken as the controls, giving an OR of 3.78 (95\% CI 1.82-7.86).

There were certain limitations in our study. Our study did not include the demographic data which might have some bearing on prevalence of $\mathrm{H}$. pylori. Some subjects might have taken antacids, proton pump inhibitors and antibiotics but missed and included in study group which may be due to sampling error. Despite the above shortcomings this meager work, we trust has proved beyond doubt that an association does prevail in the peptic ulcer disease and carcinoma stomach.

\section{Conclusion}

The present study suggests that $H$. pylori infection is the causative factor of gastroduodenal diseases in majority of cases.
H. pylori detection by endoscopic antral biopsy RUT and histology along with other diagnostic tests would increase the prevalence rate and facilitate early and specific treatment of $\mathrm{H}$. pylori infection. However, long term follow up studies are necessary to accurately evaluate the outcome of $\mathrm{H}$. pylori positive gastro duodenal diseases. Our study suggested the following salient features:

- H. pylori have a definite role as the causative agent for carcinoma stomach and different forms of gastritis.

- H. pylori are more prevalent in low socio-economic status.

- Early detection of H. pylori and its eradication and regular follow up will decrease the incidence of carcinoma stomach and different forms of gastritis.

- The H. pylori prevalence in Western Odisha was lower than that shown in the previous studies of developing Asian countries, but was significantly high in gastritis and to establish the potential association of $\mathrm{H}$. pylori with gastritis or duodenitis, and peptic ulcers.

I firmly believe that this work is a humble addition to the past studies and may infuse future works to undertake more keen studies in this field.

\section{References}

1. Alexander, Chung ANZ. J of Surg. Prevalence of H Pylori in gastric cancer in a South-east Asian Population by 1"CUrea breath test. 2001; 71:574. (156)

2. Antonioli: precursors of gastric carcinoma a critical review with a brief description of early (curable) gastric cancer Hum Pathol. 1994; 25:994-1005. (133)

3. Ashton-Key et al. Detection of Helicobacter pylori in gastric biopsy and resection specimens. J. Clin. Pathol. 1996; 49:107-111. (164)

4. Babus et al. $\mathrm{H}$ pylori and gastric cancer. Cancer letters. 1998; 125:9-15. (175)

5. Bagchi, Bhattacharya, Stohs SJ. Production of reactive oxygen sps by gastric cells in assoc. with $\mathrm{H}$. pylori. Free Radical Res. 1996; 24:439-450. (87)

6. Bayerdorffer. Association between $\mathrm{H}$ pylori infection and MALT-type lymphoma Hematol Oncol Dec 30 Ferrari AJ, Ponzoni Gastric H pyl infection, 2005. (12)

7. Bayerdorffer et al. Healing of protein losing hypertrophic gastropathy by education of $\mathrm{H}$ pylori-H pyl a factor in Menetrier's dis. Gut. 1994; 35:701-4. (111)

8. Bhatia SJ, Abraham P. Helicobacter pylori in the Indian environment. Indian J. Gastroenterology. 1995; 14:139-144. 
(134)

9. Blaser MJ. Helicobacter pylori and the pathogenesis of gastro duodenal inflammation. J. Infect. Dis. 1990; 161:626-633. $(108,123,176)$

10. Blaser MJ et al. Age at establishment of H. pylori leads to altered gastric homeostasis and neoplasia. J Clinical Investment. 1995; 94:4-8. (135)

11. Boren T. Science. Dec 17: 2625141 :1892-5 Blood group antigens in $\mathrm{H}$. pylori attachment to human gastric mucosa, 1993. (88)

12. Bousstoutas. A distinctive patterns of gene expression in premalignant gastric mucosa and gastric cancer. Cancer Res. 2003; 63:2569-2577(75)

13. Buckley et al. Helicobacter biology discovery Brt Med Bull. 1998; 54:7-16. (27)

14. Camargo MC. Age acquisition of $\mathrm{H}$ pylori infection: Comparison of two areas with contrasting risk of gastric cancer. Helicobacter. 2004; 9:262-270. (69)

15. Cammorata G. Tahir et al. Role of Dental plaque in transmission of H. pylori, J Clin. Gastroenterology. 1996; 22:147-7. (37)

16. Castro-Fernandez. $\mathrm{H}$ pylori infection in patients with bleeding ulcer disease: RUT and histology. Rev Esp. Enferm Dig. 2004; 96(6):395-8, 398-401. (155)

17. Crabtree. Indian J Gastroenterology. 2005; 24(5):220-2. (10)

18. Chuan Zhang. H pylori inf in superficial gastritis, erosive gastritis, gastric ulcer and early gastric ca W J Gastro. 2005; 11(6):791-6. (82)

19. XXXXX C. Marion, SC Delhi: Association between H. pylori infection \& gastric cancer, Lancet 1997; 341: 135962. (137)

20. Correa1992.Human gastric carcinogenesis: a multistep and multifactorial process-American Cancer Society Award lecture. Cancer Res. 52: 6735 6740. (29)

21. Cover et al:: Divergence of genetic sequences for the vacuolating cytotoxin among $\mathrm{H}$. pylori, strains J. Biol Chem 1994; 269:10566-73. (89)

22. Craanen et al. H. pylori and early gastric cancer. Gut 1994; 35:1372-74. (74)

23. Dash K, Ghoshal UC. Lancet. 1995 Jun 24: 345(8965) :1591-4.(11)

24. De Cote et al. Campylobacter - like organism and heterotrophic gastric mucosa in Meckel's diverticulum. J Clin Pathol 1989:2: 132-134. (56)

25. Denizot et al:: PAF synthesis by Helicobacter pylori Gut 1990; 1:12242. (104)

26. Desai HG; Stomach in tropics. Indian J. Gastro Enterol 1982: 1:26-34. (2,119)

27. Desai, Gill et al. Dental plaque: A permanent reservoir ofHelicobacter pylori? Scand J. Gastroenterology. 1991; 26:1205-8. $(35,179)$

28. Di camplic et al. H. pylori eradicat-idiopathChr urticaria Dig Dis Sct. 1998; 43:1226-9. (118)

29. Eaton et al. $\mathrm{H}$ pylori virulence factors in gnotobiotic piglets. Inf Immun. 1989; 57:11-1. (85)

30. Edits. Helicobacter pylori gastritis and primary gastric nonHodgkin's lymphomas. J Clin. Pathol. 1994; 47:436-439. (95)

31. Evans Jr Gastroenterology. A sensitive and specific serologic test for detection of Campylobacter pylori infection. 1989; 96(4):1004-8. (160)

32. Figueiredo, Machado. $\mathrm{H}$ pylori and Interleukin 1 genotyping: To identify high-risk individuals for gastric carcinoma. J Natl Cancer Inst. 2002; 94:1680-87. (81)

33. Freedbrug. Presence of Spirochetes in gastric mucosa. Am J. Dig Dis. 1940; 7:443-5. (19)

34. FMann D. H. pylori \& gastric cancer. Scand J Gastro Enterol. 1996; 31:23-6. (136)

35. Fukuda $\mathrm{T}$ et al. Possible role of Leukotriene in gastritis associated with campylobacter pylori, J Elam Gastroenterology. 1990; 12(1):S13. (101)

36. Genta, Hamner. The significance of lymphoid follicles in the interpretation of gastric biopsy specimens. Arch pathol Lab Med. 1994; 118:740-743. (173)

37. Gill HH, Majumdar P et al. Epidemiology of H. pylori: The Indian scenario. Ind J Gastroenterology. 1994; 12:9-11. (30)

38. Goodwin. Microbiological aspects of Helicobacter pylori (Campylobacter pylori). Eur. J Clin. Microbiol. 1990; 9:113.140. (58)

39. Goodwin et al. Unusual and distinctive ultra structure in a new spiral bacterium from the human gastric mucosa. J. Med. Microbiol. 1987; 19:257-67. (59,83)

40. Goodwin, Transfer of C. pylori and C. Mustelae to Helicobacter gen. Nov. as H. pylori comb. Nov. and H. mustela comb. Nov. Int J Syst Bacteriol. 1989; 39:397-405. (13-24)

41. Graham D et al. C. pylori detected non invasively by $13 \mathrm{C}$ urea breath test. Lancet. 1987; 1:1174-77. (153)

42. Grubel $\mathrm{P}$ et al. Vector potential of house flies for H. pylori. Gut. 1996; 39:A-88. (50)

43. Harris et al. Seroprevalence H. pylori in resident of Hospital Jr. gastro EntrolHepatol. 1995; 7:21-3. (48)

44. Handt et al. H. pylori isolated from Cat, Inf Immun. 1994; 62:2367-74. (49, 54)

45. Ho Chen RUT from non-ulcer part of stomach is superior to histology from ulcer in detection of Helicobacter pylori infection in patients with gastric ulcer. Hepatogastroenterology. 2004; 51(60):1877-80. (151)

46. The hypothesis of Huang Sridhar S Meta-analysis of the relationship between $\mathrm{H}$. pylori seropositivity and gastric cancer. Gastroenterology. 1998; 114:1169-79. (131)

47. Ina Santos et al. Prevalence of H.pylori inf\&assoc factor among adults in Southern Brazil: a population base C-S study: S. 2005; 118:1471-2458. (158)

48. Jaime et al. Diagnostic utility of invasive tests \& serology for the diagnosis of $\mathrm{H}$. pylori infection in different clinical presentation; Archives of Medical Research. 2006; 37. P.123.12(143)

49. NIH Consensus Conference. NIH Consensus Denplan in peptic ulcer disease. JAMA. 1994; 272:65-69. (28, 110)

50. Jin Kyung Kang Association of H. pylori with gastritis and peptic ulcer disease Yonsei Med J. 1991; 32(2):157-166. (68) 